\title{
Two Problem-Solving Experiences: Presential vs Virtual
}

\author{
Letícia Gabriela Martins \\ University of Minho
}

\author{
Maria Helena Martinho \\ University of Minho
}

\begin{abstract}
Problem-solving is a transversal skill considered at any level of education in Portugal. For this reason, and because it is an important part of learning mathematics, we have carried out several studies on this topic. In this article, we seek to reflect on two experiences of solving a problem, one under presential classroom format and the other virtual, in an online format. It was possible to notice similarities in the results obtained by the students and in certain wrong strategies they used, but also differences related to other strategies used, in the correction of the answers and the collective discussion of the resolutions.
\end{abstract}

Keywords: problem-solving, mathematics, presential class, virtual class, exploratory teaching, planning a class, discussion of mathematical tasks, secondary school

\section{INTRODUCTION}

Problem-solving is seen as an important part of learning mathematics (Adams \& Hamm, 2013) and a skill to prepare students for their future (Newton, 2017), whether personal or professional. In 2017, Newton advocated that students should be able to work with people from all over the world from their own homes, having to solve problems on a daily basis. This has been confirmed lately, due to the COVID-19 pandemics that we all had to face. Solving problems implies the ability to think and use acquired knowledge, hence its enormous relevance (Oldham \& Price, 2020). Furthermore, according to Schoenfeld (2013), it is an activity that leads people to do mathematics and brings the pleasure of discovery. Still, the presence of problemsolving in the classroom has been very limited (Vale et al., 2015).

In Portugal, problem-solving is present in the mathematics curriculum, along all twelve years of compulsory education. However, in line with Vale et al. (2015), students are not familiar with solving problems in the classroom. It was to try to counteract this trend that two problem-solving projects were carried out with 11th grade students, in different academic years and with different organizations: one the context of a traditional, presential classroom, the other on-line, adopting a virtual format. The question we ask was: To what extent are two experiences of solving the same problem similar and different, one caried out in a classroom with physical attendance, another adopting an online format?

In this article, to answer the question posed, a comparison will be made between two problem-solving sessions - a physical classroom session, held in the 2017/2018 school year, and a virtual session, held in the 2020/2021 school year. Both sessions were held with students from the same Portuguese public school and from the same course, Science and Technology, all attending the 11th grade. All these students were 
not used to solving problems. The organized sessions had the same duration, 90 minutes, and the same problem was proposed in both of them. In order to facilitate the reading of this article, safeguarding the identity of all participating students, the physical classroom session groups will be called $\mathrm{G} x$ and the virtual session groups will be called Groupx, where $x$ is the group number. Students attending the physical classroom will be referred by $\mathrm{S} x$, for $x$ a number, while fictitious names will be assigned to those participating in the virtual session.

\section{THEORETICAL FRAMEWORK}

It is through the confrontation with non-routine situations that opportunities to learn can be created, trying to overcome obstacles and establishing new ideas (DiNapoli et al., 2021). If this learning is to be done with understanding, we can encourage students to participate in collective discussions, in which they have opportunity to present their strategies and ideas to colleagues and argue about their reasoning and those of their peers (Rodrigues et al., 2018). Moreover, to ensure a richer discussion after solving a problem, it is necessary to choose a problem that allows different types of resolution (Martins \& Martinho, 2020). According to Mata-Pereira e Ponte (2017), however, conducting these collective discussions is a complex process because it leads to unexpected interventions by students. Therefore, it is important to be able to plan the lesson in the best possible way, so that learning opportunities are not wasted. Onuchic and Allevato (2011) present a script that can be followed when planning a class with a focus on problem solving in group, although they also mention that there is no single way to do this. The script presented by these authors includes nine points: problem preparation, individual reading, group reading, problem-solving, observing and encouraging, recording the resolutions on the blackboard, plenary, consensus, formalization of the content. This plan proposes to start by thinking in advance about the problem to be proposed, focusing namely on the objectives to be achieved or the contents to be taught. In the classroom, the problem should be given to the students, with enough time to read the statement carefully and start solving it. While students solve the problem, the teacher must observe the work of each group, clarifying possible doubts and encouraging students to improve their reasoning. Finally, the class moves on to a stage of presentation and discussion of results for all groups, ending with a synthesis to achieve the objective defined initially. This script established by Onuchic and Allevato (2011) appears to follow a model similar to that proposed by Stein et al. (2008). These authors propose to follow five steps that facilitate the discussion of a mathematical task. Stein et al. (2008) indicate, as a first step, the anticipation of interpretations that students will have of the problem, the strategies they can experiment with, possible difficulties and questions they can pose and the answers that can be given. Then, in the classroom, Stein et al. (2008) place the monitoring phase, in which the teacher circulates through the work groups to understand how the problem is being explored. During this monitoring phase, the authors indicate that the next phase can already be prepared, the phase of selecting the answers that will be presented to the whole class. When performing this selection, the teacher must also establish a sequence for the selected answers, in order to "maximize the chances that their mathematical goals for the discussion will be achieved" (Stein et al., 2008, p.329). Finally, these authors refer to the connection phase, in which the teacher is expected to reach the initially intended objective, e.g. teaching some specific content or showing students different strategies that could be used. Thus, we have five facilitating steps for a good discussion of a task, according to Stein et al. (2008), and which we seek to follow in this study: anticipating, monitoring, selecting, sequencing and connecting.

\section{SESSION PREPARATION AND METHODOLOGY}

The problem used in both sessions analyzed in this article is called "Cuts in the pizza". This problem is composed of two parts and its statement can be seen in Figure 1." 
FIGURE 1

STATEMENT OF THE PROBLEM "CUTS IN THE PIZZA"

In a pizzeria, a group of friends made the following request:

"We want a circular pizza with just 8 cuts and as many slices as possible."

\begin{abstract}
1. Assuming that the slices can have different sizes and the cuts have to be done in a straight line, how many slices can you get to satisfy the group's request?
\end{abstract}

\title{
2. What if the group had ordered the pizza with $n$ cuts? What would be the maximum number of pieces?
}

The statement in Figure 1 was exactly the statement proposed in the physical classroom project. In the virtual project, a small change was made, putting "pie" in place of "pizza", so that students would not so easily search for a solution in the internet during the session.

To plan a problem-solving session, it is helpful to anticipate what might happen in the classroom. In part 1, students were expected to answer " 37 pieces" and in part 2 the answer was expected to be written as a succession defined by recurrence. This sequence would have 2 as its first term; the remaining terms would be computed by $n$ adding to the previous term (formally, $u_{n+l}=u_{n}+n$ ), where $n$ is a natural number that represents the number of cuts made, and $u_{n}$ the number of pieces one gets by making $n$ cuts. Students have to be aware of the following pattern to reach this conclusion: each new cut had to intersect all the ones made before, but this intersection could not coincide with any existing intersection point. To become aware of this pattern, students were expected to use the strategy of drawing a figure followed by trial and error, until they realized the existence of such a pattern - that is, involving themselves in the search for a pattern strategy. In addition to establishing the goals that students should achieve, it is also important to anticipate possible difficulties. The expected difficulty was that some students could get "stuck" to the idea that the cuts would have to go through the center of the pizza, and this would not let them reach the correct answer.

In preparing the sessions, it was previously defined that specific times would be established for solving the problem in small groups and for collective discussion of the resolutions. The collective discussion would be carried out following the ascending order of the results obtained by the groups, in case they reached different solutions. In addition, we were also prepared for the possibility of some time remaining at the end of the sessions, with an extension of the problem dealing with specific cuts (e.g. parallel or perpendicular).

Both sessions discussed in this article were part of a broader pedagogical experiment as detailed below. The two sessions were guided by the first author, who was present along the entire sequence of sessions which made up the pedagogical experiments just mentioned, and carried out the corresponding data collection. The same researcher selected and analyzed all the recordings made in the two sessions, recording the relevant dialogues, difficulties, and dynamics between students throughout the sessions. Thus, the investigation followed a qualitative research approach, in the context of an interpretative paradigm. This methodology focuses on understanding what is extracted from the data, with the researcher taking an active part in data collection and analysis (Merriam \& Tisdell, 2016). These authors also state that the final product of this type of investigation is very descriptive. Coutinho (2011) refers that in the interpretative paradigm there is a strong interaction between the investigator and the investigated, in this case the students, and that the act of investigating is based on interpretations of the actions taken by the students' interpretation of what is being asked of them. 


\section{THE PHYSICAL CLASSROOM SESSION}

This first part of the pedagogical experiment underlying this study was carried out in the 2017/2018 academic year, with a class of 22 students. It was carried out in a physical classroom, lasted for a month, and included eight problem-solving sessions, the first three dealing with individual student resolutions and the remaining five with students working in groups of three or four elements. The first four sessions addressed problems directly related to the curricular topics taught at the time, while the last four were not necessarily linked to specific such topics. All student resolutions were collected: in individual sessions, all students submitted their resolution, and in group sessions, students submitted a single version accepted by all members of the respective group. In the group resolution sessions, an audio recording was made in each group, to better understand the resolution processes and the discussions that were taking place. All groups were established by the students themselves, who were organized into six groups of three elements and a group of four. The groups were fixed for all sessions.

The problem discussed in this article class was the object of the last session in the experiment sequence, session number eight. The students were already used to the rhythm of these sessions, so they entered the room and sat down according to the groups previously established. The researcher handed the problem over to all the students and recommended, as usual, that they read it carefully. At this time, it was also established that they would have 30 minutes to solve the problem in group, so that collective discussion could then be held. Along this half an hour period, monitoring was carried out, with the researcher visiting each group to understand the possible difficulties, the strategies being discussed, and the results being achieved.

After 30 minutes, the researcher realized that the students needed more time to complete their resolutions. Most groups had only been able to think about the first part of the task, so it was decided to give them 20 minutes extra to finish writing their resolutions and to think about the second part of the task as well. Also, during the monitoring phase, when faced with students raising some questions, the researcher, before answering, tried to understand if the doubt was common to the whole group and had already been discussed within it. This approach was an attempt to encourage students to work in group and to share and discuss their ideas and doubts with each other. Still, some doubts arose. Three of the seven groups had doubts about the shapes that pizza slices could take, as can be seen from the following dialogue with G2 students:

\section{S1: Teacher, the slices are supposed to have the same geometric shape?}

Researcher: Is this said in the statement?

S1: No...

Researcher: So, it's answered. If it were necessary to have the same shape, it would have to be there.

In another group, G3, a question also arose as to whether pizza slices would have to be triangular. The dialogue was similar, although the group was a little confused when told that pizza slices are not usually triangle-shaped.

\section{S2: Do the slices have to be triangular?}

Researcher: Is this said in the statement?

S2: No!

S3: It says they might not even have the same size... 
Researcher: So, if it doesn't say that... even because they might not even be quite triangular, but more of a circular sector. [taking into account a "usual" pizza slice]

\section{S3: Yeah, because this does it like that, look! This is round!}

$\mathrm{S} 2:$ Ah... what did you call it?

\section{S3: Circular sector!}

A third group, G6, had a question very similar to this one, questioning whether the slices could have the shape of a square. To this question, the researcher answered with another question: "does it say in the statement that you cannot?". The aim of these questions was to make students understand that they should restrict themselves to what was in the statement itself and work from the data provided. Sometimes students get stuck with predefined ideas and concepts which can make them unable to solve problems successfully. An example of this was observed in one of the groups, which was so focused on the idea of the cuts having to go through the center of the pizza, because this is the usual way of making the cuts, that it was unable to abandon this preconceived idea. The researcher encouraged them to think more about their resolution, but the group could not establish another line of reasoning, so they ended up not reaching the correct answer.

After the 50 minutes available for the resolution in small groups, each group delivered a resolution and the researcher established the order for the collective discussion, according to what had been previously planned. Only one of the groups presented an answer to both parts of the problem, and it was also the only group that correctly answered the task. In this session, it was not necessary to go through the phase of selecting the answers to present in the discussion, as there was only seven resolutions (one per group) and six different answers. Thus, it was possible to follow the sequence initially defined, starting with the solution with the lowest number of cuts up to the solution which lead to the highest such value. To "tie off" the two groups with the same solution, the selection criterion was based on the resolution depth. One of the groups, G5, reached its resolution resorting only to figures, as shown in Figure 2.

FIGURE 2

RESOLUTION OF THE PROBLEM BY G5

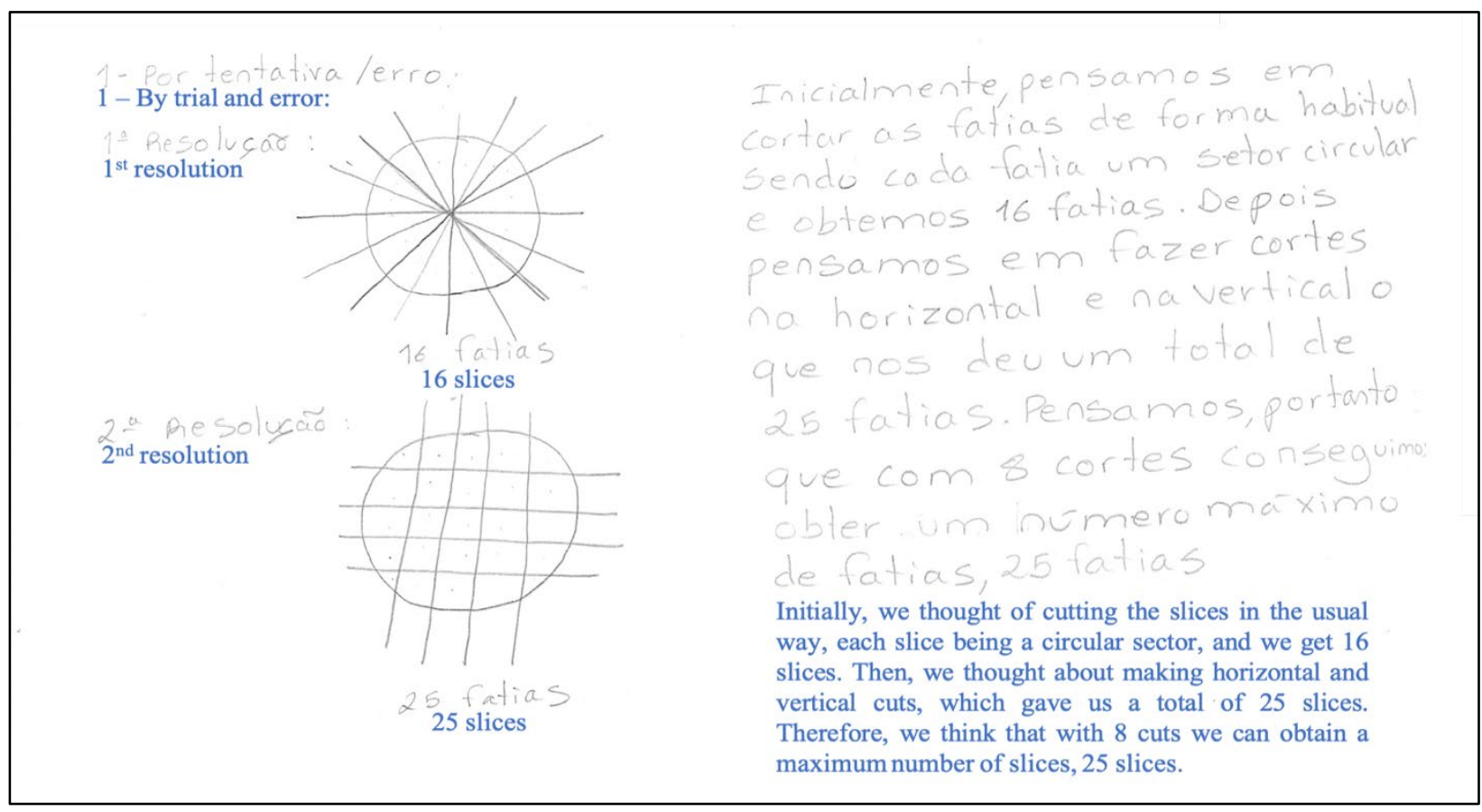


The other group, G3, in spite of having also resorted to drawings, reinforced their answer by trying to find a pattern that would also help them to answer part 2. As it was considered that this second group went a little further than G5, G5 was called first to explain its resolution to the class.

The idea of starting the discussion of results with the solutions leading to the lowest number of slices aimed at giving students the opportunity to participate more actively, namely by asking their colleagues questions about their reasoning and ideas and also questioning why they had not tried other strategies. The discussion started with group G6, which got the answer "16 pieces" because it was stuck on the idea that the cuts would all go through the center of the pizza. The group showed their idea to their colleagues, and a student from another group questioned:

S4 (G4): Why did you guys pass all the cuts by the same point? If you took one of the cuts and passed it to the side, it would already give you more than 16 slices...

S5 (G6): I agree...

S6 (G6): But this wasn't a pizza, it was a carvery! (the whole class laughs)

The question asked made the discussion richer and dynamic and allowed the S4 to develop an ability to question and critical thinking. In this way, students interacted with their peers to exchange ideas and better understand why an answer is not correct and find out possible improvements to their reasoning that could have allowed them to reach the right answer. These dynamics also gave sense to the sequence established for the discussion, as this question allowed the passage to the presentation of the next group, which despite of not having the correct answer, had already followed the tip given by S4, no making all cuts pass by the same point. They then gave way to G5, which answered " 25 slices". After one of the students in the group presented the resolution for part 1 , the researcher asked if the group had thought about part 2 . The members of the group said yes, but that they had not reached any conclusions. Here, an opportunity was created for the G3 to present their resolution, since they had also reached the answer " 25 slices" but also tried to solve part of part 2. This was followed by the presentation of the groups whose answers were "28 slices" (G2), "31 slices" (G1), and "34 slices" (G4), in that same order. So, all elements of the class began to realize what would be the ideal strategy to achieve the correct answer. Finally, G7 presented their resolution, being the only group to reach the correct answer: 37 slices. This was also the only group that managed to present an answer to part 2, also correct, writing the succession defined by recurrence. The researcher took the opportunity, then, to ask the question whether any group, now that they all knew how to correctly solve part 1, wanted to propose a possible general term for this succession. Although it was not planned that the students would arrive at this general term, G1 arrived at a possible general term, and shared it with the class: $u_{n}=1+\frac{n(n+1)}{2}$. Then, the researcher took the opportunity to question how it could be proved that the succession defined by recurrence, indicated by the G7, would, in fact, have this general term. Several students replied that they could use mathematical induction, and one of the students went to the board to write the proof of this equality, with the support of the rest of the class.

At the end of the session, it was noticeable that this phase of presentation and discussion of results was also the connection phase, as students had access to the strategies of all groups, having been allowed to share their ideas, listen to the colleagues' ideas and understand what might have failed in their own reasoning or the reasoning of the other groups. In the end, everyone was able to understand what would be the best method to make the new cuts in order to obtain the maximum number of pieces. In addition to developing problem-solving skills, the students also had the opportunity to apply their knowledge of the principle of mathematical induction, which they had previously learned. 


\section{THE VIRTUAL SESSION}

The second part of the study was carried out in the 2020/2021 academic year, with a group of 29 students, from two different classes, who enrolled voluntarily. This second pedagogical experiment was carried out as an extracurricular activity, in an online format, and had a duration of six months, with sixteen problem-solving sessions, all of them in groups and without problems directly related to the students' current curriculum. The platform used for these sessions was zoom, using simultaneous rooms, with each group in its respective room. All sessions were recorded. Researchers have access to the small group discussions, as well as to the final resolution of each group. Three groups were established for each class by the students themselves, organized into five groups of five elements each, and a group of four elements. In all sessions, students entered through a link that was previously sent by email, and later assigned to the corresponding room. At that point, a file with the problem statement was sent to all students, and the time they would have to solve the problem as a group was stipulated - which, sometimes, could be increased, when justified. After this phase of group work, one member of each group was responsible for sending a photograph or digital document with the group's resolution, via email, to the researcher. Then, the session moved on to the moment of discussion and sharing of resolutions.

The session that was used to solve the problem "Cuts in the pizza" was number fourteen. Students were already very familiar with the dynamics of these sort of sessions and with the platform, so everything went smoothly: students entered the session at the appointed time, were sent to their rooms simultaneously, and waited for the email with the problem statement. It was stipulated that they would have 30 minutes to solve the problem in group, so that the collective discussion could then take place. During this time, monitoring was carried out, with the researcher being able to follow in real time the discussions of all groups simultaneously, going to each group when asked to clear up any doubt. To help in the monitoring phase, the researcher had access to seven computers - one for each simultaneous room, and one served as a host for the entire zoom session, through which students could ask support. In this way, it was possible to make a simulation closer to the usual classroom space, with the possibility to visit and follow all groups.

The researcher realized that 30 minutes were not enough, so she extended it for another 15 minutes as all groups were a little late in their resolutions. After that time, the difficulty of the students in part 2 was notorious, as they were trying to look for a general term. To overcome this obstacle, the researcher revealed to the students that they could write the succession defined by recurrence if they did not find a general term - with this, 15 more minutes were given for students to solve in small groups, totalizing 60 minutes for this phase.

During the monitoring phase, only two questions emerged. One of them, from Group4, was about overlapping the slices:

Bianca: Can we cut the pie and overlap the two slices? Doing always like this?

Researcher: Overlap... and will that give you the maximum number of slices? I don't know... what's up with the third cut?

Bianca: It's 8 if we do it like this...

(...)

Researcher: The idea wasn't there, but well explained, it doesn't say anything against it, does it? At least this way it doesn't say anything against it, so...

This question was not considered in the anticipation phase, so it became more complicated to respond promptly to these students. It was decided to encourage students to clearly justify the resolution they were going to present and to read the statement well so that they could guarantee that there was nothing there in conflict with the strategy they were following. This failure in the anticipation phase was not considered serious, as it would leave room for the students themselves, in the discussion phase, to argue whether or not 
they thought this resolution was acceptable. In addition to this doubt, another one emerged in Group5, which was also unanticipated:

Clara: We want to know if we could cut the pie like this on the sides, like this horizontally?

Researcher: No... because you don't even know how tall the pie is, so it's kind of weird to cut it like that... I mean, I don't know.

Clara: But even if the pie was, I don't know, $1 \mathrm{~cm}$ thick, you could cut it... or not?

Researcher: Okay, let me think... the idea isn't that, but basing the answer well, we can see... but the idea wasn't there.

Edgar: We can try to solve it according to the idea and then we do this "attachment"...

Cintia: Assuming the pie has a considerable height...

This issue was not considered either, but it was reinforced that all lines of reasoning can be valid, as long as they are well founded and explained. However, the students in this group abandoned the idea of horizontal cuts which, thus, was not brought to the final discussion.

An hour after the students started solving the problem in small groups, each group emailed the resolution and were all called back to the main room. The order for the collective discussion was then stipulated as in the presential session. Again, it was not necessary to go through the selection phase. This is because three correct answers were presented to part 1, but the three groups presented different solutions for part 2. The answers given by the three groups with incorrect answers were all different - one of the groups even followed a method of resolution distinct from all others. This was the case of Group4, which followed the idea of overlapping the slices, so it was decided to leave this group's resolution to the end. The discussion then started with the group that answered " 22 pieces", the resolution can be seen in Figure 3.

After this presentation, the researcher challenged participants to ask questions or leave suggestions that could serve for Group 2 to find a correct solution. Only one student, from one of the other groups, responded to the challenge, indicating that Group2 could have made other types of cuts, and not just mostly parallel ones. This was followed by the presentation of a new group, who answered " 28 pieces". This time, no one wanted to make any comment or question to the group, despite the conclusion being the same of Group2: they needed to have more varied cuts, and not just parallel and perpendicular ones. 
FIGURE 3

RESOLUTION OF THE PROBLEM BY GROUP2

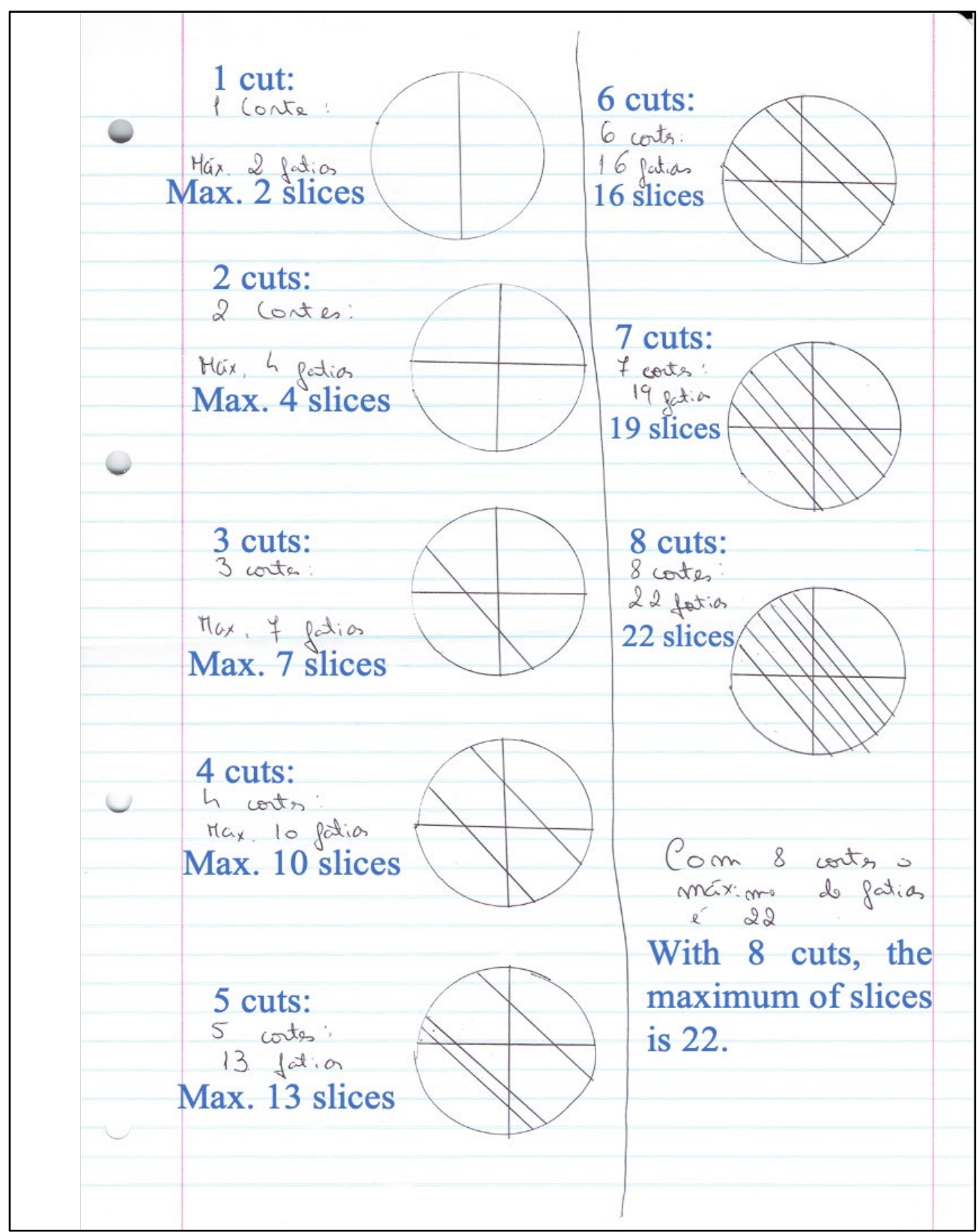

Then, it was the turn of Group3, which had the correct answer to part 1 but not to part 2. This group ended their presentation saying that the answer to part 2 would be "there is no maximum number of pieces", justifying that the sequence would not be limited. After being challenged to comment on the resolution, a student from Group6 said:

Nelson: Group 6 reached a general term in question 2!

This intervention set the tone for Group1, a group that correctly answered the two parts of the problem, presenting a succession defined by recurrence. At the end of the presentation by one of the members of 
Group1, another member added that they had also arrived at a general term, but that they had not included it in their resolution because they had arrived at that general term "for nothing". After saying what the general term was, it was confirmed that it was the correct general term, time came for Group6, who had the problem currently solved and had put the general term in their answer. This group was asked about the method they used to reach the general term and the students responded that it was only tentative. However, after looking closely at the recording of this group, we realized that the students researched sequences that had similar characteristics to what they found in this problem.

Finally, the session moved to Group4 to discuss the resolution with overlapping slices. The researcher opened the discussion by saying that she did not expect such a resolution and would be waiting to hear the comments from the other groups.

Fernanda: I think this is a bit strange because when they make the third cut, they are cutting the pie several times... so it's not just one cut, but as many cuts as there are pieces of pie that are overlapping.

Only this student, from Group1, spoke, ending the discussion of this session.

As in the physical classroom case, the connection phase was also built up throughout the presentation and discussion of results phase, since results were presented gradually and allowed a better understanding to all students who did not reach the correct answer.

\section{PHYSICAL CLASSROOM VS VIRTUAL}

There were some differences between the two sessions presented. The first difference noticed is in the strategies followed by the students. In the physical classroom session, the students followed the expected cut strategy, without having raised issues with other types of cuts. In the virtual session, we had two groups proposing cuts different from what was expected - overlapping slices and making horizontal cuts. This difference in the sessions can be attributed to the fact that the students in the virtual session have more previous experiences, within the corresponding pedagogical experiments, than the students in the physical classroom session, when it comes to problem-solving. With more experiences, the students had already developed a greater ability to think "outside the box", triggering unexpected strategies. Furthermore, the fact that "pies" were used instead of "pizzas" in the virtual session may have contributed to these new strategies emerging in the virtual, but not in the physical classroom format.

Another difference was in the number of correct answers since in the physical classroom session only one group correctly answered part 1 , while in the virtual session there were three groups with a correct solution to the same part of the task. In addition to the fact that students in the virtual session already had more extensive previous experience in problem-solving, the fact that they used digital tools also made a difference, as it is simpler to simulate cut through drawings on the computer than manually. Actually, some groups did, even if not further discussed above.

The last difference noticed was in the discussion phase, which proved to be more productive and stimulating for the students in the physical classroom session, with greater involvement of students, more student interventions reacting to peer presentations, showing their critical spirit and actively contributing so that all students could follow the lines of reasoning that would led to the correct solution. In spite of their more extensive experience, students in the virtual session were less interventional, contributed little to the connection phase that was expected to happen simultaneously with the presentation of results and discussion phase.

Finally, similarities were also registered in the two sessions. In both cases the responses obtained by the groups were different, a factor that contributed positively to the collective discussion planned for the final phase of the session. In addition, it was possible to observe an obstacle common to most groups that failed to reach the correct answer: they stuck to cuts performed in parallel or perpendicularly. 


\section{CONCLUSION}

The process of planning a lesson can be challenging for a teacher, especially when the aim is to solve a problem. Planning a class along these lines is related to the practice of exploratory teaching, following the five facilitating steps of Stein et al. (2008). The selection of the problem to be proposed to the students must be thought of according to the objectives one intends to achieve, and this selection is an important part of the anticipating process, as well as predicting possible doubts and the strategies to be used (Martins \& Martinho, 2020). In the classroom, the monitoring phase helps the teacher to understand what students are doing and how they are thinking, and also clarify doubts and challenge students. Within this phase, the teacher also begins to prepare the collective discussion, going through the selection and sequencing steps. As mentioned by Rodrigues et al. (2018), conducting these collective discussions, so that they are productive, can be challenging for the teacher, since the entire process of organizing the discussion influences student participation. This was also mentioned by Mata-Pereira e Ponte (2017), who indicated that the teacher needs to have the ability to guide and manage the course of the discussion and also the content of it.

In the two experiences reported in this article, the anticipation phase was similar, so that no distinctions were felt that influenced this study from the outset. Thus, the lesson plan was the same in both cases, with one of the biggest differences being in the format of the class: one was in person with all the elements from the same class, the other was virtual with elements from two different classes of the same school. The only issue to note at this stage, which may have influenced some differences in the two sessions, is that the problem in the first session was about a "pizza" and the problem in the second session was about a "pie". This small change in the statement required a new reflection on the proposed problem, namely in anticipating strategies and questions that students could pose, a reflection that was not made. We also noticed three differences between the two sessions: in the strategies followed by the students, in the number of correct answers, and in the discussion phase. In the physical classroom session, all groups followed the same cutting strategy, only one group managed to answer correctly, and the discussion was more productive and stimulating for the students. In the virtual session, the students thought of different ways to make the cuts, three groups were able to answer correctly to part 1 - and two of them to part 2 -, and the collective discussion was almost non-existent since the students had less tendency to intervene and ask questions to colleagues. The differences in cutting strategies may have arisen from the fact that the statements presented were not exactly the same. The small difference in the statement may have implied different lines of reasoning from the students, also causing a failure in the anticipating phase, since the latter was made only in relation to the statement concerned with cutting a pizza, rather than a pie. The difference regarding the collective discussion, however, may be explained by the dynamic created (involving a single class or two classes together), but it may also be related to the format of the sessions. Actually, most students who participated in the virtual sessions indicated lately that they would have enjoyed the sessions much more if they were in physical interaction, having even mentioned that physical classroom sessions would be more productive, fun, and dynamic.

\section{ACKNOWLEDGEMENTS}

This paper is supported by Fundação para a Ciência e a Tecnologia (FCT) through a PhD scholarship (SFRH/BD/147510/2019). Further support by CIEd - Research Centre on Education, projects UIDB/01661/2020 e UIDP/01661/2020, Institute of Education, University of Minho, through national funds of FCT/MCTES-PT. 


\section{REFERENCES}

Adams, D., \& Hamm, M. (2013). Demystify math, science, and technology: Creativity, innovation, and problem solving (Second Edition). Rowan \& Littlefield Education.

Coutinho, C.P. (2011). Metodologia de Investigação em Ciências Sociais e Humanas: Teoria e Prática. Almedina.

DiNapoli, J., Amenya, M., Van Den Einde, L., Delson, N., \& Cowan, E. (2021). Simulating remote support for mathematical perseverance through a digital sketching application. Journal of Higher Education Theory and Practice, 21(4), 41-52. https://doi.org/10.33423/jhetp.v21i4.4208

Martins, L.G., \& Martinho, M.H. (2020). A problem-solving experience: The teacher's perspective. In B. Di Paola \& P. Palhares (Eds.), Connections and understanding in mathematics education: Making sense of a complex world (pp. 319-324).

Mata-Pereira, J., \& Ponte, J.P. (2017). Enhancing students' mathematical reasoning in the classroom: Teacher actions facilitating generalization and justification. Educational Studies in Mathematics, 96(2), 169-186. https://doi.org/10.1007/s10649-017-9773-4

Merriam, S.B., \& Tisdell, E.J. (2016). Qualitative Research: A Guide to Design and Implementation. Jossey-Bass A Wiley Brand.

Newton, N. (2017). Math problem solving in action: Getting students to love word problems, grades 3-5. Routledge. https://doi.org/10.4324/9781315465050

Oldham, E., \& Price, E. (2020). Large-scale studies of attainment: focus on TIMSS and PISA. In L. Leite, E. Oldham, A.S. Afonso, F. Viseu, L. Dourado, \& M.H. Martinho (Eds.), Science and mathematics education for 21st century citizens: Whallenges and Ways forward (p.xv). Nova Science Publishers.

Onuchic, L.D.L.R., \& Allevato, N.S.G. (2011). Pesquisa em Resolução de Problemas: Caminhos, avanços e novas perspectivas. Bolema - Mathematics Education Bulletin, 25(41), 73-98.

Rodrigues, C., Menezes, L., \& da Ponte, J.P. (2018). A prática de uma professora de Matemática ao conduzir uma discussão coletiva sobre sequências. Boletim GEPEM, 73, 32-49. https://doi.org/10.4322/gepem.2018.015

Schoenfeld, A.H. (2013). Reflections on problem solving theory and practice. The Mathematics Enthusiast, 10(1), 9-34.

Stein, M.K., Engle, R.A., Smith, M.S., \& Hughes, E.K. (2008). Orchestrating Productive Mathematical Discussions: Five Practices for Helping Teachers Move Beyond Show and Tell. Mathematical Thinking and Learning, 10(4), 313-340. https://doi.org/10.1080/10986060802229675

Vale, I., Pimentel, T., \& Barbosa, A. (2015). Ensinar matemática com resolução de problemas. Quadrante, 24(2), 39-60. Retrieved from https:/quadrante.apm.pt/index.php/quadrante/article/view/55/47 